\title{
ethic \\ É POSSÍVEL UMA CONSTITUIÇÃO SEM ESTADO? UMA ANÁLISE DA PROPOSTA HABERMASIANA DE POLÍTICA MUNDIAL SEM GOVERNO MUNDIAL
}

\author{
CONSTITUTION WITHOUT A STATE? AN ANALYSIS OF \\ HABERMASIAN PROPOSAL FOR GLOBAL POLITICS WITHOUT A \\ WORLD GOVERNMENT
}

CRISTINA FORONI CONSANI ${ }^{1}$

(UFPR/Brasil)

\begin{abstract}
RESUMO
Este artigo apresenta e analisa a proposta habermasiana de uma política mundial sem governo mundial. Isso é realizado em três momentos: primeiramente, apresenta-se o modelo cosmopolita habermasiano e o seu sistema de instituições em múltiplos níveis, o qual abarca a tese da possibilidade da existência de uma Constituição sem Estado; em um segundo momento, serão apresentadas algumas objeções a esta tese, principalmente as críticas dirigidas recentemente a Habermas por William Scheuerman. Por fim, será analisado em que medida a teoria habermasiana oferece respostas às críticas formuladas.

Palavras-chave: Habermas; Cosmopolitismo; Democracia; Constituição; Estado.

\section{ABSTRACT}

This paper presents and analyzes the habermasian proposal for global politics without a world government. This will be done in three moments: first, the habermasian cosmopolitan model is presented; it will be stressed the multilevel system of institutions, which embrace the thesis of Constitution without a State; second, will be presented some objections to Habemas's thesis elaborated recently by William Scheuerman; finally, this paper analyzes to what extent habermasian theory offers answers to these objections.
\end{abstract}

Keywords: Habermas; Cosmopolitanism; Democracy; Constitution; State.

\section{Introdução}

O cosmopolitismo político tem experimentado um notável renascimento nas últimas duas décadas. Por cosmopolitismo político entende-se, seguindo-se uma definição de Thomas Pogge, uma teoria que se compromete com um ideal político concreto de uma ordem global (cf. POGGE, 2002, p. 169). Uma das questões centrais em disputa no âmbito das teorias cosmopolitas, entretanto, é como deve ser esta ordem global. Entre os teóricos contemporâneos que têm se debruçado sobre este tema, há uma certa preponderância daqueles que consideram que qualquer tipo de ordem ou 
democracia global é melhor visualizada não em termos de um Estado ou governo mundial com autoridade centralizada, mas sim como um sistema de governança em múltiplos níveis, com a dispersão da autoridade para a tomada de decisões. É exatamente a este grupo que se filia Habermas ao propor, em seu próprio modelo cosmopolita, a tese de que é possível existir uma Constituição sem Estado.

O objetivo deste artigo é apresentar e problematizar esta tese habermasiana. Isso será feito em três momentos: primeiramente, será apresentado o modelo cosmopolita habermasiano e o seu sistema de instituições em múltiplos níveis, o qual abarca a tese da possibilidade da existência de uma Constituição sem Estado; em um segundo momento, serão apresentadas algumas objeções a esta tese, principalmente as críticas dirigidas recentemente a Habermas por William Scheuerman. Por fim, será analisado em que medida a teoria habermasiana oferece respostas às críticas formuladas.

\section{O modelo cosmopolita habermasiano e a tese da Constituição sem Estado}

O modelo cosmopolita habermasiano tem sido delineado desde a segunda metade dos anos de 1990 e pode ser encontrado em ensaios que integram obras como: A Inclusão do Outro (1996); A Constelação PósNacional (1998); O Ocidente Dividido (2004); Sobre a Constituição da Europa (2011) e Na Esteira da Tecnocracia (2013). Esse modelo pode ser apresentado a partir de dois argumentos centrais: um argumento empírico (ou o seu diagnóstico de época), que aponta para os limites da política realizada dentro dos estados nacionais no contexto da globalização; e um argumento político-normativo, o qual consiste em sua proposta para enfrentar os problemas causados pela globalização. A apresentação do cosmopolitismo habermasiano feita aqui seguirá esses argumentos.

Argumento empírico: O diagnóstico de época de Habermas analisa, por um lado, as transformações da economia e da política na era da globalização e, por outro lado, ele interpreta a evolução normativa da sociedade mundial apontando para as possibilidades de aprimoramento jurídico e moral na arena global. Partindo dessas considerações, três aspectos do diagnóstico de época feito por Habermas em sua defesa de um projeto de direito e de política cosmopolita requerem atenção, são eles: i) os problemas que afetam a soberania e a política no âmbito interno dos Estados; ii) a evolução do direito internacional; iii) a ruptura com o processo de racionalização e civilizatório em marcha no direito internacional promovida pela atuação norte-americana após os atentados de Onze de Setembro. 
i) Ao revisitar o projeto cosmopolita kantiano, Habermas reconhece que os desafios colocados tanto pelas catástrofes do século $X X$ quanto pelos problemas sociais da globalização impulsionaram a retomada das ideias de uma justiça cosmopolita nos termos defendidos por Kant. A globalização tem como consequência deixar vulneráveis as sociedades em seu modo de organizar a política internacional, a política interna e a economia. A globalização impõe mudanças no funcionamento do direito público internacional no que diz respeito à soberania dos Estados e à nítida separação entre política interna e externa, uma vez que agentes privados passam a ter força econômica e política outrora só possível para Estados.

[a]gentes não-estatais como empresas transnacionais e bancos privados com influência internacional esvaziam a soberania dos Estados nacionais que eles mesmos atacam de um ponto de vista formal. Hoje em dia, cada uma das trinta maiores empresas do mundo em operação movimenta uma receita maior que o produto nacional bruto de noventa dos países representados na ONU, considerados individualmente (HABERMAS, 2002, p. 195).

Diante de tais transformações, Habermas chama a atenção para os limites impostos à política pela economia, pois enquanto a economia atua em âmbito global, a política continua a se organizar predominantemente de forma nacional, tornando-se, assim, incapaz de se impor à economia no que diz respeito a questões como a eliminação da desigualdade extrema, regulações trabalhistas e ambientais, contaminação atômica, entre outras.

ii) O segundo aspecto do diagnóstico de época habermasiano é sua avaliação positiva da evolução do direito internacional a partir da segunda metade do século XX. Ele reconhece que desde o final da II Guerra Mundial ocorreu uma grande evolução do direito internacional, evolução esta que se intensificou após o fim da guerra fria com o fortalecimento de instituições supranacionais (tais como as Nações Unidas e a União Europeia), a juridificação dos direitos humanos na Declaração Universal e a crescente importância de organizações transnacionais como as Organizações Mundiais do Comércio, da Saúde, do Trabalho, o G8. Essas mudanças, segundo Habermas, apontam para a criação de meios de governança global.

Habermas obviamente não é ingênuo a respeito das limitações dessas organizações e da própria atuação da ONU, por vezes omissa ${ }^{2}$ e em outras restrita em razão de sua estrutura organizacional e orçamentária. ${ }^{3}$ Contudo, ele assinala algumas inovações importantes que foram introduzidas pela Carta da ONU e pela Declaração Universal dos Direitos Humanos, as quais 
mostram que o direito internacional não é mais apenas um direito de Estados. São elas:

a) a admissão dos cidadãos individuais como sujeitos do direito internacional - o preâmbulo e o art. $1^{0}$ da Carta da ONU, assim como a Declaração Universal dos Direitos Humanos atribuíram caráter normativo aos direitos humanos e passaram a admitir que uma reclamação individual possa ser feita também por indivíduos e não apenas por Estados (cf. HABERMAS, 2011, p. 224-225);

b) centralização do poder punitivo no Conselho de Segurança da ONU - estabelece-se a proibição fundamental à violência, que não pode ser invalidada por tratados internacionais; no caso de violação de regras a ONU pode usar violência militar na função de polícia (apesar da previsão legal, isso não foi de fato implementado e o Conselho de Segurança tem permitido que os Estados-Membros mais potentes implementem as sanções por ele adotadas) (cf. HABERMAS, 2011, p. 226-228);

c) orientação para a inclusão - a ONU abre-se para a adesão de qualquer Estado que se obrigar a cumprir os fundamentos da Carta e das declarações de direitos humanos e não apenas para Estados configurados como democracias liberais, isto é, abre-se inclusive para regimes despóticos e criminosos. Por um lado, o preço a pagar é a contradição entre os princípios declarados da organização mundial e os padrões de direitos humanos de fato praticados. Entretanto, a tolerância com as contradições entre princípios e práticas abriria um diálogo entre países do Ocidente e do Oriente, com maior sensibilidade para as diferenças culturais, étnicas e religiosa (cf. HABERMAS, 2011, p. 229-231).

iii) O terceiro aspecto do diagnóstico de época de Habermas é a identificação da interrupção da marcha racionalizadora e civilizatória da juridificação do direito internacional. Em seu entendimento, esta ruptura foi causada pela política recente do governo norte-americano que, após o atentado de Onze de Setembro, passou a ignorar o direito internacional e a agir de acordo com suas próprias concepções do certo e do errado, sobrepondo ao processo de juridificação em curso uma espécie de moralização ou eticização no âmbito das relações internacionais. Desse modo, Habermas aponta, no âmbito da política internacional, para uma contraposição entre o direito e moral - moral aqui compreendida como os valores éticos e convicções morais próprios dos norte-americanos (considere-se, por exemplo, a noção bastante difundida da luta contra o mal na qual o significado de bem e mal é atribuído pelos próprios interessados). Assim, justificações normativas próprias de um povo são colocadas no lugar de procedimentos prescritos pelo direito internacional. O que se verifica é, segundo Habermas, um falso universalismo quando um 
Estado "substitui o direito positivo pela moral e pela ética em questões de justiça internacional" (HABERMAS, 2011, p. 146).

O diagnóstico de época de Habermas mostra, portanto, que os Estados se encontram hodiernamente diante de dois modelos inadequados - uma juridificação insuficiente e uma moralização unilateral (cf. COHEN, 2018, p. 144). Por um lado, a juridificação tem ocorrido por meio de procedimentos juridicamente estabelecidos por uma organização mundial inclusiva, mas impotente e que toma decisões seletivas. Por outro lado, as regras das relações internacionais passam a ser ditadas por uma ordem política unilateral de um hegemon que se apresenta como "bem intencionado" (HABERMAS, 2011, p. 164).

Argumento político-normativo: O projeto cosmopolita habermasiano intenta afastar-se de ambos os modelos. Ele aposta na constitucionalização do direito internacional em bases democráticas, o que implica a reformulação da organização mundial existente e o desenvolvimento do projeto de "uma política interna mundial sem governo mundial" (Weltinnenpolitique ohne Weltregierung), que abriga a ideia de Constituição sem Estado). 4

O projeto de uma "política mundial sem governo mundial" está intimamente ligado à ideia segundo a qual uma república mundial ou estado de povos não são as únicas instituições que podem dar forma ao projeto cosmopolita kantiano. O receio de que um governo mundial possa ser despótico ou autoritário, e que possa colocar em risco o pluralismo e a complexidade social e cultural, faz com que Habermas delineie um modelo cosmopolita que tem como ponto de partida estruturas e instituições já existentes (a ONU, os blocos regionais que têm na União Europeia seu melhor exemplo, as organizações internacionais como a Organização Mundial do Comércio, a Organização Mundial da Saúde e a Organização Internacional do Trabalho, entre outras, e também os estados nacionais) e proponha uma constituição política da sociedade mundial descentralizada com um sistema de múltiplos níveis. Seriam eles: supranacional ou global, transnacional e, nacional.

O nível supranacional ou global pressupõe uma organização mundial reformada a fim de conseguir desempenhar de forma efetiva e não seletiva suas funções vitais, que seriam basicamente a manutenção da paz e a proteção aos direitos humanos, sem precisar assumir a forma estatal de uma república mundial (cf. HABERMAS, 2011, p. 189). Na esteira dessa proposta, a ONU deveria ser reorganizada como uma comunidade politicamente constituída de Estados e cidadãos. Aqui, Habermas pensa em uma Assembleia Geral ou Parlamento Mundial constituído por cidadãos e por Estados, no qual deveriam ser levadas em consideração as pretensões 
dos cidadãos do mundo (direitos de igual tratamento e de igualdade distributiva) e dos cidadãos de cada Estado nacional (cf. HABERMAS, 2012, p. 95). Deveria também haver uma reforma no Conselho de Segurança e nas Cortes de Justiça a fim de que estes conseguissem realizar efetiva e regularmente a garantia da paz e a proteção aos direitos humanos, com possibilidade real de centralização do poder de sanções e do uso de tropas.

O nível transnacional é delineado a partir da ideia de blocos regionais, cujo melhor exemplo seria a União Europeia. Tratar-se-ia de um conjunto de organizações intermediárias, no âmbito de conferências e sistemas de negociação permanentes, os grandes atores com capacidade de atuação global trabalhariam com os problemas difíceis de uma política interna mundial não só coordenadora, mas também configuradora, com especial atenção para os problemas da economia mundial e da ecologia (cf. HABERMAS, 2011, p. 189-190). No modelo habermasiano, o nível transnacional seria o principal responsável pela implementação da justiça social, pois as regulações criadas neste nível teriam justamente a responsabilidade de impor limites aos mercados de trabalho, de bens e de crédito, de modo a proteger trabalhadores, o meio ambiente e a sociedade em geral.

A ordem democrática transnacional deverá se organizar de modo distinto do que ocorre no Estado nacional. Trata-se de pensar em um desenho institucional baseado no conceito de soberania partilhada, o qual implica compreender como sujeitos ativos do poder soberano tanto cidadãos quanto Estados. Esse desenho institucional, contudo, não seria o de uma federação, na qual os estados membros figuram como poderes constituídos. Numa democracia transnacional, os estados-membros devem figurar como poder constituinte e, por essa razão, manteriam competências mais fortes no interior da coletividade constituída. Habermas propõe que imaginemos uma convenção constitucional da qual fariam parte, por um lado, cidadãos de grandes blocos regionais (por exemplo, europeus ou latino-americanos etc.) e, por outro lado, Estados, os quais decidiriam os contornos da União Política a ser constituída (cf. HABERMAS, 2014, p. 112115).

O nível nacional seria aquele constituído pelos Estados nacionais tais como existem contemporaneamente. Assumir-se-ia, contudo, que o direito de soberania seria restringido para observar as normas de garantia de paz e de proteção aos direitos humanos e também as diretrizes econômicas e sociais erigidas no âmbito transnacional que poderiam impulsionar a solidariedade além das fronteiras nacionais. Ademais, é no nível nacional que continuaria a ocorrer a formação da opinião e da vontade e a legitimação democrática em sentido forte. 
A corrente de legitimação, diz Habermas, "se estenderia ininterruptamente desde os Estados nacionais, passando por regimes regionais, como a União Europeia, até chegar ao âmbito da organização mundial" (HABERMAS, 2012, p. 102). Tem-se, assim, um modelo de legitimação democrática em sentido forte - aquela que ocorre por meio dos procedimentos democráticos situados dentro do estado-nação, e uma legitimação democrática em sentido fraco - aquela da arena global.

Segundo Habermas, na constelação pós-nacional, os elementos que foram fusionados na forma histórica do Estado nacional, a saber, o caráter estatal, a solidariedade cidadã e a constituição se separam e precisam de outra configuração, pois a sociedade mundial atual é "rompida culturalmente e altamente estratificada". Desse modo, o "Estado não é uma condição necessária para a existência de ordens constitucionais" (HABERMAS, 2011, p. 191). Assim, segundo ele, seria um erro construir a constitucionalização do direito internacional como uma continuação do desenvolvimento constitucional do Estado no nível global, pois já não se tem mais apenas uma associação não hierárquica de atores coletivos (estados) baseada no princípio da igual soberania (a sociedade internacional), mas sim organizações supra e transnacionais de uma ordem cosmopolita que regula uma comunidade internacional dualista, composta de Estados e de indivíduos. À luz do seu caráter não estatal, as organizações supranacionais não possuem os elementos característicos dos Estados, quais seja, o monopólio do uso legítimo da violência, a possibilidade de cobrança de impostos e o aparato militar do Estado moderno (cf. COHEN, 2018, p. 146).

Na esteira de Hauke Brunkhorst, Habermas sugere que o caminho da constitucionalização para a sociedade mundial politicamente organizada é mais próximo à trajetória de ordens jurídicas pré-modernas, nas quais as diferentes camadas de poder representadas pela nobreza, pela Igreja ou pelas cidades faziam contratos de poder com o rei numa espécie de "império da lei sem autolegislação", do que às constituições republicanas revolucionárias. Trata-se da ideia de restrição recíproca e de balanceamento dos poderes que governam. Essa tradição foi reformulada na versão liberal da constitucionalização encontrada na tradição inglesa do Rule of Law e também na tradição alemã do Rechtsstaat. Esses tipos constitucionais objetivam uma juridificação do poder político, mas a juridificação tem "o sentido de domesticação da violência por meio da divisão institucional e da regulação conforme o procedimento de relações de poder existentes" (HABERMAS, 2011, p. 193), ou seja, não promovem uma ruptura com as relações de poder existentes nas sociedades, apenas criam meios de controle desse poder político. As constituições revolucionárias, de modo 
distinto, "derrubaram as relações de poder existentes em favor de um poder racional novo, proveniente da vontade dos cidadãos unidos e formada racionalmente" (HABERMAS, 2011, p. 193).

Habermas contrapõe, então, dois modelos constitucionais: o liberal cujo foco recai sobre os mecanismos de limitação e equilíbrio do poder político, e o republicano - cuja ênfase repousa sobre o ideal de autogoverno. Em seu entendimento, as constituições do tipo liberal são recomendadas para comunidades políticas que vão além do estado nacional. Segundo ele,

\begin{abstract}
essas constituições regulam a atuação conjunta dos atores coletivos com o objetivo de limitar reciprocamente o poder, conduzem o jogo de poder pacificado de acordo com o procedimento para os trilhos da conformidade com os direitos humanos e deixam para os tribunais as tarefas de aplicação e de formação do direito sem um envolvimento direto com as demandas e controles democráticos. Então aqui a 'constitucionalização' do direito internacional não tem o sentido republicano de uma juridificação das relações internacionais (HABERMAS, 2011, p. 194).
\end{abstract}

O modelo liberal projetado para a ordem política global afasta-se da concepção republicana de constituição que Habermas havia delineado para a política nacional ( $\mathrm{e}$, mais recentemente, também para a democracia transnacional), com o foco na soberania popular e na legitimidade democrática em sentido forte.

Esse desenho institucional pensado por Habermas, justamente por não propor a superação dos estados-nação soberanos, mas sim sua integração em uma nova estrutura constitucional global, caracteriza-se como uma posição intermediária entre o realismo político - que nega a possibilidade de acordos políticos coletivos no âmbito internacional, ${ }^{5}$ e projetos cosmopolitas mais ambiciosos, os quais avançam em direção à proposta de um Estado ou República mundial. ${ }^{6}$ Essa posição intermediária, contudo, acaba por atrair o criticismo de ambos os lados. Algumas dessas críticas serão apresentadas a seguir, principalmente a partir das ambiguidades apontadas por William Scheuerman ao projeto habermasiano. 


\section{Problemas da tese da "política mundial sem governo mundial" e da ideia de Constituição sem Estado}

Em seus escritos mais recentes sobre este tema, ${ }^{7}$ Habermas tem defendido um modelo de legitimação democrática mais forte no âmbito da democracia transnacional. Mas essa mudança no que diz respeito ao nível transnacional (o fortalecimento de instituições e de práticas democráticas em grandes blocos como a União Europeia) em nada altera a sua tese da possibilidade de uma constituição sem Estado. No âmbito da democracia transnacional, que tem a União Europeia como principal objeto de análise, Habermas continua a negar a necessidade de os estados europeus se unirem em uma espécie de federação; no âmbito global, também não considera desejável a criação de um poder político central com tarefas mais abrangentes do que a proteção aos direitos humanos e a garantia da paz.

Um dos principais críticos de Habermas no que diz respeito à proposta de uma política interna mundial sem governo mundial é o cientista político William Scheuerman. A seguir, apresentarei essas críticas para, posteriormente, avaliar em que medida a teoria cosmopolita de Habermas oferece elementos para refutá-las.

Ambiguidades e tensões no âmbito transnacional: Na proposta de governança global em múltiplos níveis defendida por Habermas, há ambiguidades no que diz respeito à quantidade de elementos do Estado tradicional que organizações regionais, como a União Europeia, precisam ter. No nível transnacional, Habermas teria em mente uma espécie de equilíbrio político entre grandes potências (os global players), que se estabeleceria a partir de uma ONU reformada e fortalecida operando em conjunto com organizações transnacionais não estatais poderosas (como a União Europeia) ou grandes potências como EUA e China. Apesar de seu ponto de partida conceitual aparentemente anti-estatista, os Estados, embora não a grande maioria dos estados-nação existentes, continuariam sendo atores importantes e talvez predominantes em seu esquema. Essa estrutura encontra-se em tensão com a reinvindicação de que os estadosnação podem e devem preservar elementos tradicionais de sua soberania pois, com a exceção das grandes potências capazes de ser protagonistas no âmbito da globalização econômica, a maioria dos estados-nação provavelmente não teria autoridade significativa. Questões como proteção ambiental, regulação econômica e financeira, seriam da competência do nível transnacional, enquanto a proteção dos direitos humanos e a segurança seriam deixadas sob a responsabilidade da ONU. A competência dos estados-nação, assim, parece ser uma competência residual, típica de modelos federalistas (cf. SCHEUERMAN, 2008a, p. 486; 2008b, p. 162164). 
Ambiguidades e tensões no âmbito global: Apesar de insistir na distinção entre Constituição e Estado, o principal alvo de Habermas não são os Estados per se ou o seu desenvolvimento num nível pós-nacional, mas sim uma república federal global ou algum tipo de estado mundial democrático. No entanto, apesar de recusar a ideia de uma república mundial, Habermas também busca uma ONU fortalecida e um Conselho de Segurança mais eficaz, capaz proteger os direitos humanos e garantir a paz, especialmente em oposição às grandes potências que, como os EUA hoje, tendem a sobrepor-se ao direito internacional. Mas como a ONU poderia conseguir esse poder sem possuir ao menos alguns elementos do Estado Moderno? Mesmo que não houvesse formalmente o monopólio legítimo da violência, parece que tal tarefa exige um amplo esforço político e militar para agir contra Estados que, como os EUA contemporaneamente, desconsideram o direito internacional ao iniciar guerras de agressão, praticar a tortura e detenções por tempo indeterminado. Para afastar a ideia de um Estado mundial, Habermas tem recorrido aos processos bemsucedidos de aprendizagem histórica que resultaram em transformações nas práticas tradicionais de soberania do Estado. Em O Ocidente Dividido, ele toma a ONU e a União Europeia como exemplos de instituições que têm exercido suas funções sem recorrer a um elemento central dos Estados, a saber, a coerção. Ele enfatiza esse elemento no seguinte excerto:

O Estado não é uma condição necessária para a existência de ordens constitucionais. Assim, comunidades supranacionais como a ONU ou a União Europeia não dispõem daquele monopólio dos meios para o exercício legítimo da violência que serve como garantia para a soberania interna e externa do Estado jurídico, administrativo e fiscal moderno; no entanto, elas reivindicam a primazia do direito supranacional em relação às ordens jurídicas nacionais. $O$ direito europeu estabelecido em Bruxelas e em Luxemburgo é especialmente respeitado pelos Estados-membros por mais que sejam eles que conservem os meios aquartelados de violência (HABERMAS, 2011, p. 191).

Mesmo que a União Europeia forneça essa interessante experiência da observância das regras sem a necessidade do recurso ao monopólio legítimo da violência, isso não pode ser facilmente estendido à arena global. Habermas também apoia a tese segundo a qual a ONU poderia proteger os direitos humanos sem ter que assumir os atributos de um Estado democrático e insiste que, nestes termos, a ONU promoveria apenas "deveres claramente negativos de uma moral universal de justiça - o dever 
de se abster de guerras de agressão e de crimes contra a humanidade" (HABERMAS, 2011, p. 199). Em sua avaliação, a governança global não exige a transformação da ONU em uma república federal global, pois suas principais tarefas derivam de uma moral universalista relativamente incontroversa e restrita da justiça, qual seja: evitar a guerra e proteger os direitos humanos. Aqui, a questão levantada por Scheuerman é se, de fato, a ONU poderia ter tal poder sem alguns elementos rudimentares do Estado. Mesmo sem o monopólio legítimo da violência, seria preciso que esta instituição mantivesse considerável poder político e militar para agir contra Estados fortes como os EUA. Contudo, Scheuerman ressalta que qualquer instituição que reivindique autoridade para decidir quem viverá e quem morrerá requer legitimidade democrática e, quiçá, alguns elementos centrais do Estado democrático de direito (cf. SCHEUERMAN, 2008a, p. 487; 2008c, p. 145).

Déficit de legitimação democrática: Outra crítica dirigida ao modelo cosmopolita habermasiano é a existência de um déficit de legitimação democrática. Habermas tem sido criticado por não reconhecer a indispensabilidade do Estado para a implementação de medidas como a preservação da paz, a proteção aos direitos humanos básicos e a implementação de regulações sociais e econômicas além das fronteiras dos estados nacionais. Rainer Schmalz-Bruns (2007) argumenta que é preciso ver o Estado, ou organizações semelhantes ao Estado, como elementos essenciais à democracia e ao ideal de autogoverno. Ele chama a atenção para as dificuldades que surgem quando se tenta desconectar o Estado moderno das aspirações políticas e jurídicas da modernidade. Assim, igualdade e liberdade democráticas são melhor garantidas por procedimentos justos e razoáveis que podem possibilitar que a ação dos cidadãos tenha algum impacto nas decisões políticas. Esse tipo de influência só pode ser alcançado por instituições associadas a elementos significativos do Estado. Também nesse sentido são as críticas tecidas pela politóloga italiana Nadia Urbinati aos modelos de democracia cosmopolita. Segundo ela, em si mesma a ideia de democracia cosmopolita é problemática em razão do cenário global, uma vez que é mais fácil levar para a arena política global temas e questões do que pessoas. O cenário global, diz ela, "compreende questões interrelacionadas ao invés de um demos integrado" (URBINATI, 2003, p. 80). Um símbolo dessa distinção, em seu entendimento, é o vocabulário utilizado pelos defensores da democracia cosmopolita, que insistem na substituição da palavra "governo" pela palavra "governança". Desse modo,

Diferentemente do governo, a governança refere-se a 'políticas'(policies) específicas ao invés de a uma política 
(politics) geral porque ela não implica uma estrutura de tomada de decisão vinculativa. Seus destinatários não são o 'povo' como sujeito coletivo, mas 'as populações' que podem ser afetadas por questões globais como meio ambiente, migrações ou o uso dos recursos naturais (URBINATI, 2003, p. 80)

Na mesma linha de argumentação, Scheuerman sustenta que a participação e a deliberação democrática só fazem sentido se as pessoas puderem esperar que suas vozes resultarão em alguma medida eficaz e vinculativa para si mesmas e para os outros. O Estado, ou dispositivos institucionais semelhantes ao Estado, desempenha um papel constitutivo neste processo. Assim, a ideia de uma política mundial sem governo mundial reduziria as funções do Estado moderno a uma espécie de "poder decisório não regulamentado" e obscureceria suas conquistas normativas necessárias (representação, participação, influência nos processos decisórios, controle do poder político pela via democrática, etc.) (cf. SCHEUERMAN, 2008a, p. 488; 2014, p. 423).

Confusão entre as instâncias decisórias no nível nacional, transnacional e global. Segundo Scheuerman, o modelo de governança em múltiplos níveis proposto por Habermas, ao tentar se distanciar de um federalismo global, promove uma confusão entre as competências de cada um dos níveis. Que direitos e deveres os cidadãos podem exigir de cada um dos níveis? Sem alguma hierarquia entre os níveis nacional e pós-nacional, ou pelo menos sem a existência de um árbitro comum mediando as decisões nestes níveis, inevitavelmente haverá conflitos entre eles, seja no âmbito dos atores políticos, seja no âmbito das instituições e será difícil alcançar uma normatização jurídica coerente. Tendo isso em vista, é possível questionar se um federalismo global não proporcionaria um enfoque mais transparente para a tomada de decisões entre níveis distintos e hierarquicamente organizados (cf. SCHEUERMAN, 2008a, p. 488).

Checks and balances e a concessão ao realismo político: Um dos principais adversários teóricos de Habermas é a tradição do realismo político e pensadores como Carl Schmitt. No entanto, em algumas formulações, Habermas parece introduzir algumas ideias que lembram justamente a teoria do realismo político. Ele tem descrito a governança transnacional como um processo de contestação política entre atores globais (por exemplo: blocos regionais como a UE, grandes potências como EUA e China, OMC, etc), os quais teriam recursos políticos e econômicos suficientes para efetivamente produzir um sistema de equilíbrio - uma espécie de equilíbrio de forças gerado pelo conflito de interesses entre atores com poderes equivalentes. Habermas tem manifestado a esperança de que a EU forneça 
um contrapeso político às políticas neoliberais dos EUA. Em um ensaio conjunto com Jacques Derrida Habermas argumentou que a EU deveria adotar uma política externa capaz de contrabalançar o unilateralismo hegemônico dos EUA (cf. HABERMAS, 2011, p. 69-80). Tais propostas ecoam a visão realista de que apenas um equilíbrio significativo de poder no cenário internacional é capaz de garantir a aplicação relativamente consistente da lei internacional. Assim, Habermas acaba por inserir elementos da tradição realista em seu modelo cosmopolita. Esse elemento reforça uma leitura segundo a qual o modelo de governança global de fato concedeu às instituições estatais e similares no nível transnacional poderes substanciais. Isso faz alguns críticos, como Scheuerman, concluir que o que Habermas propôs não é, na realidade, governança global sem governo global, mas o aprimoramento da autoridade estatal nos níveis transnacional e supranacional (cf. SCHEUERMAN, 2008a, p. 489-490; 2014, p. 419).

\section{O cosmopolitismo habermasiano como uma utopia realista}

As críticas apresentadas acima apontam para algumas ambiguidades e tensões entre os três níveis delineados no modelo cosmopolita habermasiano e indicam também algumas dificuldades de realização do projeto da constitucionalização do direito internacional sem o recurso a elementos centrais do Estado Moderno. Proponho aqui analisar essas críticas a partir de dois elementos essenciais para as teorias democráticas cosmopolitas hodiernas, quais sejam, a legitimidade democrática e o papel de instituições semelhantes ao Estado. Além de essenciais, esses elementos também parecem estar conectados, uma vez que as críticas referentes ao déficit democrático dos modelos cosmopolitas assentam-se justamente na ausência ou insuficiência das instituições de tomadas de decisão que foram se fortalecendo ao longo dos anos no contexto dos Estados Democráticos de Direito.

No que diz respeito à legitimação democrática, como apresentado na seção I deste artigo, o modelo habermasiano apoia-se em uma concepção unitária ou monista de legitimação, pois embora o enfoque da legitimidade seja diferente em cada nível ou âmbito de governo, Habermas insiste que a mesma legitimidade subjacente está operando em todos os níveis (cf. CRONIN, 2011, p. 211). Ademais, no que diz respeito especificamente a este ponto, tanto as críticas dirigidas aos seus primeiros ensaios sobre a constitucionalização do direito internacional quanto a práxis política internacional dos últimos tempos levaram Habermas a advogar por um modelo mais robusto no que diz respeito às instituições democráticas. Nesse sentido, suas reflexões mais recentes sobre a democracia no nível 
transnacional, que tomam as práticas jurídico-políticas da União Europeia como exemplo, podem ser compreendidas como um esforço na direção de delinear um modelo de participação democrática em sentido forte para além do estado-nação.

Na obra Na Esteira da Tecnocracia, a crítica de Habermas volta-se para as medidas adotadas pelo Conselho Europeu com base em argumentos tecnocráticos. Ele junta-se, então, aos críticos da governança e faz um alerta sobre a necessidade de se fortalecer a política diante da economia:

sob a etiqueta inocente de 'governance', os regimes tecnocráticos se expandirão na medida que não se consegue explorar as fontes de uma legitimação democrática também para as autoridades supranacionais. É inadiável uma transnacionalização da democracia. Esse projeto atinge a relação de polícia e mercado e se depara com a resistência política previsível do lado econômico-liberal (HABERMAS, 2014, p. 111/112).

Se é certo que a oposição de Habermas à tecnocracia e ao predomínio dos elementos econômicos sobre os elementos político-democráticos e de solidariedade no processo de integração europeia levaram o filósofo a repensar seu modelo de democracia transnacional e a acentuar a necessidade de fortalecer os espaços de participação democrática (a proposta da soberania compartilhada entre indivíduos e Estados como membros de um poder legislativo transnacional é uma das principais características dessa mudança), também não se pode negar que, mesmo recusando a ideia de um Estado ou República mundial, o desenho institucional habermasiano, mesmo no âmbito global, não destoa demasiadamente daqueles que apontam para a inevitabilidade de um Estado Mundial. Ao idealizar reformas para a ONU, Habermas defende que a Assembleia Geral deveria ser delineada na forma de um Parlamento Mundial, composto tanto por cidadãos quanto por Estados. Essa proposta, com algumas variações, também se repete em defensores de um Estado Mundial. ${ }^{8}$

Ainda a respeito da legitimidade democrática, Habermas parece apostar no processo de aprendizagem que ocorre, para indivíduos e instituições, a partir do momento em que as propostas de constitucionalização do direito internacional começam a ser colocadas em prática. Segundo ele,

Também não podemos subestimar a influência, com potencial de transformação, da consciência dos discursos internacionais 
que são desencadeados pela construção de novas relações jurídicas. Por meio da participação em disputas sobre a aplicação desse novo direito, as normas que a princípio só haviam sido reconhecidas verbalmente por funcionários e cidadãos passam a ser cada vez mais internalizadas. Assim, também os Estados nacionais aprendem a entender a si mesmos simultaneamente como membros de comunidades políticas maiores (HABERMAS, 2011, p. 246).

Nesse sentido, os avanços já ocorridos e que ainda podem ocorrer no âmbito de um direito cosmopolita (que não tem apenas os Estados, mas também os indivíduos como sujeitos de direitos) acabam por proporcionar a construção de uma cultura política cosmopolita.

Desse modo, parece que as críticas referentes ao déficit democrático do modelo cosmopolita habermasiano perdem força, seja pelo desenho institucional proposto pelo filósofo, que conta com a participação política dos cidadãos nos processos de tomada de decisão nos níveis nacional, transnacional e global, seja pela confiança subjacente a este projeto de que o desenvolvimento de instituições democráticas em nível global levará ao fortalecimento de uma cultura política mais solidária, tolerante e cosmopolita.

No que diz respeito às críticas voltadas à recusa de uma instituição política central que exerça as funções do Estado moderno, me parece que tais objeções não são afastadas tão facilmente. Por um lado, a posição intermediária de Habermas faz concessões a ambas as posições a respeito da política internacional: ao realismo político, concede que seria irrealista e, quiçá, inexequível defender um governo mundial, o qual inevitavelmente seria remoto, não representativo e possivelmente opressivo. Às posições mais ambiciosas, concede que é preciso contar com instituições intermediárias de governo que possam lidar com questões não mais passíveis de serem resolvidas apenas pelos Estados nacionais. De acordo com Cronin, a grande força e inovação do projeto habermasiano reside justamente na combinação de elementos realistas e constitucionais em um modelo unificado (cf. CRONIN, 2011, p. 214).

Contudo, Scheuerman parece ter razão ao afirmar que, embora Habermas negue a figura do Estado, seu projeto acaba por depender de alguns elementos centrais dos Estados modernos para sua própria exequibilidade. Dois dos argumentos de Scheuerman são bastante relevantes nesse sentido, quais sejam: a necessidade de um árbitro imparcial para decidir sobre os conflitos que inevitavelmente surgirão entre os diferentes agentes nos distintos níveis de governo, e a atuação do Conselho de Segurança da ONU caso seus poderes venham de fato a ser 
fortalecidos. Principalmente no que diz respeito à atuação da ONU na garantia da paz e na proteção dos direitos humanos, Habermas tem acentuado a necessidade de o Conselho de Segurança ter um exército próprio, independente dos Estados, para atuar no cumprimento de seus deveres institucionais com poder de polícia. Ou seja, ainda que se considere que o no nível global estaríamos diante de um modelo de Estado mínimo, comprometido com a vida e com a segurança, essa instituição ainda conteria o monopólio legítimo da violência.

Para concluir, pode-se considerar que o modelo cosmopolita habermasiano tenta estabelecer uma espécie de utopia realista no sentido de que busca propor um modelo ideal de democracia transnacional fazendo uma série de concessões à realidade social. Ele parte de um argumento empírico segundo 0 qual os atores políticos nacionais foram desempoderados pela globalização meramente econômica e, a partir desse diagnóstico, apresenta um argumento político-normativo segundo o qual para que a democracia possa dar voz aos atores políticos é preciso pensar em instituições democráticas globais. Ele procura estabelecer um desenho institucional transnacional em múltiplos níveis (local, regional e global), no qual a autoridade de tomada de decisões é descentralizada, tanto no intuito de evitar o surgimento de um poder político despótico, quanto no intuito de preservar a pluralidade de identidades culturais e sociais e, desse modo, nega a possibilidade de se pensar em um Estado Global ou em República Federal Mundial (proposta consubstanciada na tese da possibilidade de uma constituição sem Estado). Contudo, quando analisamos as ambiguidades e tensões presentes neste modelo, o que parece surgir é um conjunto de instituições que, embora enfaticamente negado por Habermas, acabam por assumir características centrais do Estado moderno. Nas palavras de Scheuerman, apesar das afirmações de Habermas em contrário, "seu próprio modelo de reforma global parece um Estado, caminha como Estado e fala como Estado" (SCHEUERMAN, 2008a, p. 491). 


\section{Notas}

1 Professora Adjunta do Departamento de Filosofia da Universidade Federal do Paraná e professora permanente do Programa de Pós-Graduação em Filosofia da UFPR. E-mail: crisforoni@yahoo.com.br. ORCID iD: https://orcid.org/0000-00016072-9053.

2 Sobre a omissão da ONU Habermas narra o caso de Ruanda, no qual o Conselho de Segurança havia sido alertado sobre a iminência de um massacre e mesmo assim não autorizou uma intervenção, permitindo o massacre de 800 mil pessoas, a maioria delas pertencentes à minoria tutsi. Segundo Habermas, esse fato mostra o quanto a ONU ainda está amarrada aos interesses nacionais em detrimento das obrigações globais da comunidade internacional. Cf. HABERMAS, Jürgen. O projeto kantiano e o Ocidente dividido. In: O Ocidente dividido: Pequenos escritos políticos X. Trad. Bianca Tavolari. São Paulo: Unesp, 2011, p. 237-238.

3 Sobre o orçamento da ONU, Habermas ressalta que é algo em torno de $4 \%$ do orçamento anual da cidade de Nova York. Cf. HABERMAS, Jürgen. O projeto kantiano e o Ocidente dividido. In: O Ocidente dividido: Pequenos escritos políticos X. Trad. Bianca Tavolari. São Paulo: Unesp, 2011, p. 241, nota 93.

4 Cf. HABERMAS, Jürgen. A Constelação Pós-Nacional: ensaios políticos. Trad. Márcio Seligmann-Silva. São Paulo: Littera Mundi, 2001, p. 131-132; HABERMAS, Jürgen. O projeto kantiano e o Ocidente dividido. In: O Ocidente dividido: Pequenos escritos políticos X. Trad. Bianca Tavolari. São Paulo: Unesp, 2011, p. 188ss.

${ }^{5}$ A posição realista é apresentada por Habermas a partir da análise e refutação das teses de Carl Schmitt a respeito da política internacional. Ainda sobre a posição realista, Ciaran Cronin apresenta a seguinte síntese: "Os desafiantes clássicos a todas as formas de cosmopolitismo são as chamadas posições realistas, as quais veem as relações internacionais como um sistema anárquico cujos atores, isto é, estados-nação e, em particular, "grandes potências", são divididas por diferenças culturais e históricas intransponíveis, as quais tornam impossíveis os acordos duradouros sobre objetivos políticos coletivos. Para os realistas, as relações internacionais são irredutivelmente competitivas e o direito internacional não pode se basear em nada mais robusto normativamente do que acordos voluntários; assim, para os realistas, a ideia de "constitucionalização" do direito internacional, que envolveria grandes potências delegando parte de sua soberania para um corpo supranacional, está simplesmente em desacordo com a natureza do sistema internacional" (CRONIN, 2011, p. 213, tradução própria).

6 Nesse sentido, Otfried Höffe fala de uma "República Mundial Complementar" como imprescindível para a salvaguarda universal do direito (cf. HÖFFE, 2005, capítulos 10 e 11). Também Alexander Wendt tem defendido a inevitabilidade de um Estado Mundial (cf. WENDT, 2003, pp. 491-542).

7 Ver, por exemplo, os textos contidos nos livros "Sobre a Constituição da Europa" e "Na Esteira da Tecnocracia".

8 Nesse sentido, por exemplo, são as propostas de Otfried Höffe, que assume a necessidade de um Estado ou República mundial complementar. Segundo Höffe, a 
República mundial seria complementar e não substitutiva aos Estados nacionais. Entre outras propostas, ele sugere que a Assembleia Geral da ONU deveria ser bicameral, composta também por representantes dos cidadãos (cf. HÖFFE, 2005, p. 391). 


\section{Referências bibliográficas}

BAYNES, Kenneth. Habermas's Model for a Two-track Cosmopolitan Order. In: BECKMAN, Ludvig; ERMAN, Eva (eds.). Territories of Citizenship. London/New York: Palgrave Macmillan, 2012, pp. 123-145.

COHEN, Jean L. The Constitutionalization of International Law. In: BRUNKHORST, Hauke; KREIDE, Regina; LAFONT, Cristina. The Habermas Handbook. New York: Columbia University Press, 2018.

CRONIN, Ciaran. Cosmopolitan democracy. In: FULTNER, Barbara (ed.) Jürgen Habermas: Key Concepts. London/New York: Routledge, 2011, pp. 196-221.

HABERMAS, Jürgen. A Constelação Pós-Nacional: ensaios políticos. Trad. Márcio Seligmann-Silva. São Paulo: Littera Mundi, 2001.

. A inclusão do outro: estudos de teoria política. Trad. Georg Sperber e Paulo Astor Soethe. São Paulo: Loyola, 2002.

. Der Gespaltene Westen. Frankfurt am Main: Suhrkamp, 2004.

. Na esteira da tecnocracia. Trad. Luiz Repa. São Paulo: Unesp,

2014

. O Ocidente dividido: Pequenos escritos políticos X. Trad. Bianca Tavolari. São Paulo: Unesp, 2011.

- Sobre a Constituição da Europa: um ensaio. Trad. Denilson Luis Werle, Luiz Repa e Rúrion Melo. São Paulo: Unesp, 2012.

HÖFFE, Otfried. A democracia no mundo de hoje. Trad. Tito Lívio Cruz Romão. São Paulo, Martins Fontes, 2005.

POGGE, Thomas. World Poverty and Human Rights. Cambridge: Polity Press, 2002.

SCHEUERMAN, William. All Power to the (State-less?) General Assembly! In: Constellations Volume 15, No 4, pp. 487-492. 2008a

. Cosmopolitanism and the world state. In: Review of International Studies (2014), 40, 419-441.

. Frankfurt School Perspectives on Globalization, Democracy, and the Law. London/New York: Routledge, 2008b. 
. Global Governance without Global Government? Habermas on Postnational Democracy. In: Political Theory, Volume 36 Number 1, February, pp. 133-151, 2008c.

SCHMALZ-BRUNS, Rainer. An den Grenzen der Entstaatlichung. Bemerkungen zu Jürgen Habermas'Modell einer 'Weltinnenpolitik ohne Weltregierung'. In: NIESEN, Peter; HERBORTH, Benjamin (eds). Anarchie der kommunikativen Feiheit. Jürgen Habermas und die Theorie der internationalen Politik. Frankfurt: Suhrkamp, 2007, pp. 269-93.

URBINATI, Nadia. Can Cosmopolitical Democracy Be Democratic? In: ARCHIBUGI, Daniele (ed). Debating Cosmopolitics. Londres: Verso, 2003, pp. 67-85.

WENDT, Alexander. Why a World State is Inevitable. In: European Consortium for Political Research, Vol. 9(4): 491-542, 2003. 